
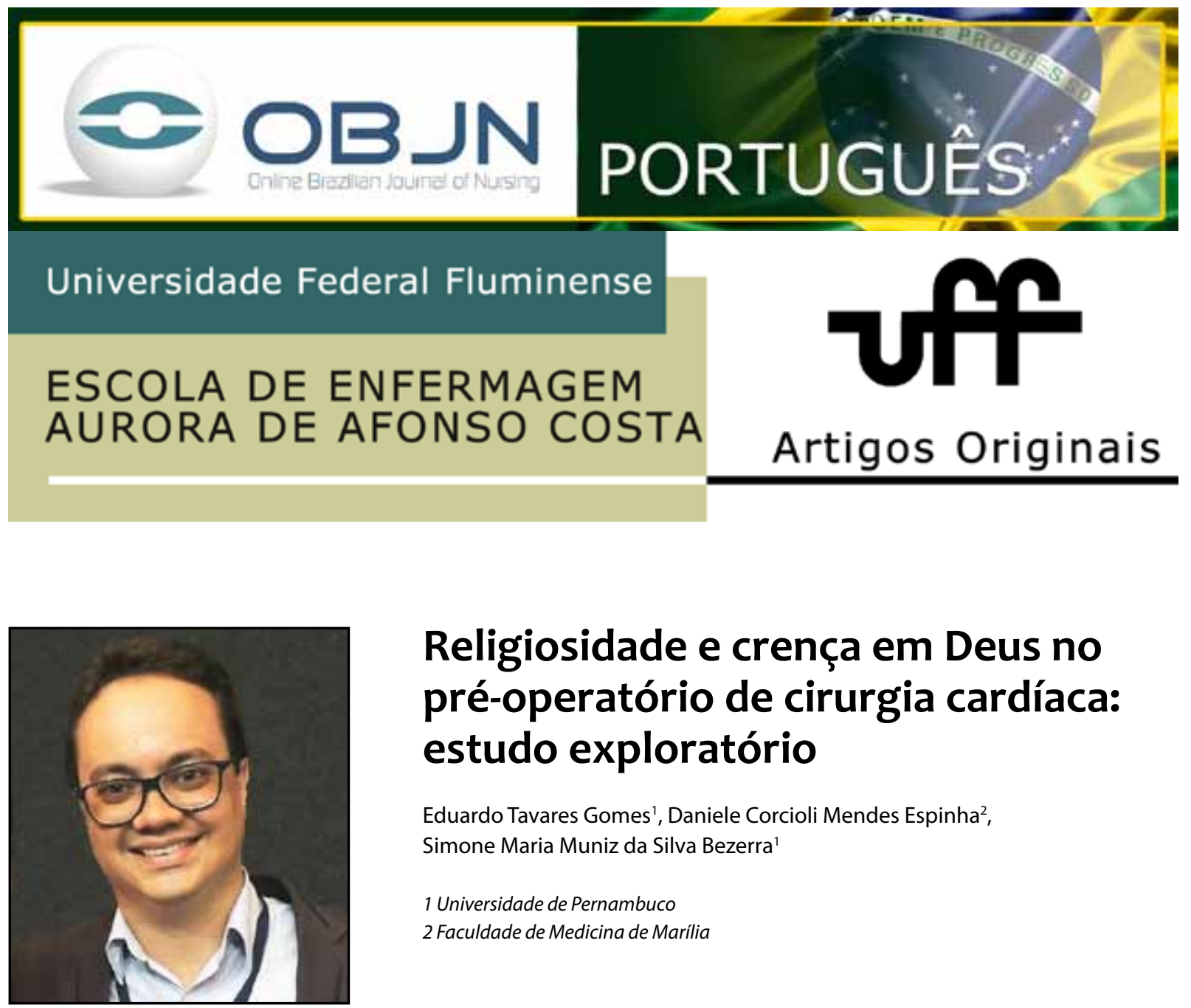

\title{
Religiosidade e crença em Deus no pré-operatório de cirurgia cardíaca: estudo exploratório
}

\author{
Eduardo Tavares Gomes' ${ }^{1}$ Daniele Corcioli Mendes Espinha², \\ Simone Maria Muniz da Silva Bezerra' \\ 1 Universidade de Pernambuco \\ 2 Faculdade de Medicina de Marília
}

\section{RESUMO}

Objetivo: Analisar as relações entre a crença em Deus e a religiosidade no período pré-operatório de cirurgia cardíaca. Método: Estudo exploratório, qualitativo, em que utilizou-se uma entrevista semiestruturada e a análise de Bardin para a extração dos conteúdos. Foram entrevistados 12 pacientes que se apresentavam como crentes em Deus, de qualquer religião e com elevado bem-estar espiritual avaliado previamente por uma escala validada. A questão norteadora da pesquisa foi: há relação entre o seu Deus e o seu adoecimento? Resultado: Os discursos versavam sobre as relações entre Deus, adoecimento e cirurgia cardíaca e o enfretamento da doença e do trâmite cirúrgico. A mazela não foi relacionada veementemente ao castigo divino, mas o conhecimento da progressão da doença cardíaca relacionada a hábitos de vida modificáveis revelou-se ligado a sentimentos de culpa. Conclusão: A crença em Deus repercutiu positivamente no encontro com um novo sentido para o trâmite cirúrgico.

Descritores: Espiritualidade; Período Pré-Operatório; Cirurgia Cardíaca; Enfermagem 


\section{INTRODUÇÃO}

Espiritualidade e religiosidade são temas que vêm despertando cada vez mais o interesse acadêmico. As necessidades espirituais podem ser compreendidas como a satisfação de um crescimento espiritual que torna a pessoa mais sociável, esperançosa e em paz com sua divindade ou transcendência. Já os conceitos de religiosidade estão diretamente relacionados ao vínculo do indivíduo com uma religião, ser divino ou Deus, que pode ser experimentada individualmente ou de forma coletiva ${ }^{(1)}$.

A cirurgia cardíaca apresenta implicações na ansiedade e depressão que têm sido estudadas nos últimos anos, contudo pesquisas recentes vem demonstrando relações significativas com a espiritualidade e religiosidade do paciente ${ }^{(1-2)}$. Apesar disso, intervenções direcionadas aos pacientes nesse âmbito são escassas, geralmente vinculadas à capelania hospitalar ou a grupos religiosos e raramente institucionalizadas.

Na relação dos temas com a ansiedade e a depressão no pré-operatório, uma investigação conduzida com 150 pacientes em pré-operatório de cirurgia geral revelou que os que possuíam alto nível de religiosidade apresentavam menores níveis de ansiedade ${ }^{(3)}$. Ao se avaliar as estratégias de enfrentamento utilizadas por pacientes em pré-operatório de cirurgia cardíaca, outro estudo nacional relatou que a modalidade de coping sustentativo, que inclui a espiritualidade, foi utilizado em $50 \%$ dos $\operatorname{casos}^{(4)}$. A análise qualitativa também já demonstrou a presença de sentimentos positivos e de busca por fé e esperança na religiosidade diante o evento da cirurgia cardíaca ${ }^{(5-6)}$. Outro estudo observou, por meio de entrevistas, o elevado valor da utilização de recursos espirituais no enfrentamento da cirurgia cardíaca ${ }^{(6)}$.

Uma coorte de 335 pacientes submetidos à cirurgia cardíaca, excluindo-se as de emergência e o transplante cardíaco, por 30 meses acompanhou e concluiu mais do que a implicação da religiosidade na diminuição da ansiedade e depressão pré-operatórias. Lançando mão de escalas validadas para avaliação de espiritualidade, religiosidade, práticas e crenças religiosas, coping religioso/espiritual, otimismo e esperança, apresentou resultados ao longo do tempo e mostrou que os melhores índices nesses aspectos repercutiam em maior crescimento existencial, no sentido de melhor desenvolvimento psicoespiritual dos indivíduos que se submeteram à experiência cirúrgica(7).

Outra publicação dos mesmos autores, também em coorte para avaliar ansiedade e depressão a longo prazo (30 meses) em relação a aspectos espirituais-existenciais no pré-operatório, revelou a prece, o otimismo e a esperança como preditores de menores índices de depressão e a religiosidade intrínseca e a esperança como preditores de menor ansiedade ${ }^{(1)}$. Ainda nessa mesma coorte, os autores divulgaram a prece como fator de proteção à fadiga ao longo do seguimento, enquanto que a ansiedade pré-operatória foi avaliada como fator de aumento na avaliação da fadiga física e mental ${ }^{(8)}$.

A crença em Deus serve de base à religiosidade e traz implicações para o paciente no enfrentamento da doença tanto de forma positiva quanto de forma negativa. Tendo por referência a diretriz que estes estudos vêm apontando na compreensão desse fenômeno, um aprofundamento se faz possível e necessário, mergulhando ainda na questão e buscando compreender como a crença em Deus repercute no enfrentamento da doença cardíaca, em particular no trâmite cirúrgico.

Por meio desta investigação, objetivou-se analisar as relações entre a crença em Deus e o bem estar espiritual no período pré-operatório de cirurgia cardíaca. 


\section{MÉTODO}

Trata-se de um estudo de natureza exploratória, com abordagem qualitativa, realizado nas enfermarias cirúrgicas do Pronto-Socorro Cardiológico Universitário de Pernambuco.

Utilizou-se uma entrevista semiestruturada que continha como roteiro inicial um questionário para caracterização dos sujeitos (gênero, idade, renda, atividade laboral, escolaridade, situação marital, número de filhos e religião) e dados da cirurgia (tipo da cirurgia, tempo de internamento, tempo de pré-operatório etc.). Esses dados são apresentados com recursos de estatística descritiva (média \pm desvio padrão, frequências absolutas e relativas).

Para seleção dos sujeitos participantes, os pacientes eram convidados a participar da pesquisa e, após a assinatura do Termo de Consentimento Livre e Esclarecido, era aplicada a Escala de Bem-Estar Espiritual (EBE). A EBE é um instrumento subdividido em duas subescalas (de 10 itens cada): uma de bem-estar religioso (BER) e outra de bem-estar existencial (BEE). Os itens referentes ao BER contêm uma referência a Deus, expressando como o paciente se sente com as demandas da sua religiosidade no momento; e os de BEE referem-se à sensação de encontro com o sentido e o comprometimento com algo significativo na vida, retratando crises existenciais e conflitos subjetivos. A escala possui 20 questões que devem ser respondidas por meio de uma escala Likert de seis opções. O total da escala é a soma das pontuações destas 20 questões e os escores podem variar de 20 a $120^{(9)}$.

Foram selecionados 12 pacientes que se afirmaram crentes na existência de Deus, praticantes de qualquer religião e que obtiveram escores maiores que 100 na EBE, indicando um elevado valor de bem-estar espiritual no período pré-operatório. Os tipos de cirurgia incluídos foram a revascularização miocárdica e as trocas ou plastias de valva. Os pacientes estavam todos cientes da cirurgia e da data próxima, em até cinco dias. Excluíram-se pacientes com cardiopatias congênitas ou com a comunicação verbal prejudicada pelo quadro clínico.

Após a abordagem inicial procedia-se a entrevista, tendo como questão norteadora: há relação entre o seu Deus e o seu adoecimento? As entrevistas foram gravadas, transcritas e submetidas à análise de conteúdo proposta por Bardin. Por meio dessa análise, pode-se inferir além da própria mensagem transcrita, por meio de indicadores, quantitativos ou não, relativos à condição em que o conteúdo foi produzido.

As entrevistas foram realizadas nas enfermarias, à beira do leito, em outubro de 2014 e duraram, em média, 21 minutos. Após o esclarecimento acerca do objetivo do contato, ao paciente era dada a possibilidade de escolher a presença ou não do acompanhante no decorrer. Aos que concordaram com a permanência, foi esclarecido ao acompanhante que ele não poderia participar das respostas, emitir parecer ou expressar qualquer reação. As falas transcritas são apresentadas indicando os pacientes pela letra $\mathrm{P}$ seguida dos números de 1 a 12, de forma a não permitir a identificação dos pacientes. $A$ pesquisa foi aprovada pelo Comitê de Ética da instituição (CAAE: 30622414.7.0000.5192).

\section{RESULTADOS}

\section{Caracterização dos sujeitos}

A amostra foi tida por conveniência quanto ao tamanho, observado os critérios de inclusão. Não houve predominância entre os gêneros, a média de idade foi de $58,58 \pm 11,8$ anos, maioria de aposentados (83,33\%), escolaridade baixa $(5,5 \pm 5,14$ anos de estudos) e renda média de 1,83 $\pm 1,32$ salários mínimos (considerados em 
$\mathrm{R} \$ 724,0)$. Houve predominância de casados $(53,8 \%)$, com média de $3,2 \pm 2,6$ filhos. (tabela 1 )

Tabela 1: Dados sociodemográficos e da cirurgia dos pacientes entrevistados. Recife, 2014

\begin{tabular}{|c|c|}
\hline Idade (md $\pm d p)$ & $58,58 \pm 11,8$ \\
\hline \multicolumn{2}{|l|}{ Sexo (n/\%) } \\
\hline Masculino & $6 / 50,0$ \\
\hline Feminino & $6 / 50,0$ \\
\hline \multicolumn{2}{|l|}{ Procedência (n/\%) } \\
\hline Interior & $8 / 66,7$ \\
\hline Capital & $1 / 8,33$ \\
\hline Região Metropolitana & $3 / 25,0$ \\
\hline \multicolumn{2}{|l|}{ Atividade laboral (n/\%) } \\
\hline Desempregado & $1 / 8,33$ \\
\hline Aposentado & $10 / 83,3$ \\
\hline Autônomo & $1 / 8,33$ \\
\hline Anos de estudo (md $\pm d p)$ & $5,50 \pm 5,14$ \\
\hline Renda (md $\pm d p)$ & $1,83 \pm 1,32$ \\
\hline \multicolumn{2}{|l|}{ Situação conjugal (n/\%) } \\
\hline Casado & $7 / 53,8$ \\
\hline Divorciado & $2 / 16,67$ \\
\hline Solteiro & $2 / 16,67$ \\
\hline Viúvo & $1 / 8,33$ \\
\hline \multicolumn{2}{|l|}{ Religião (n/\%) } \\
\hline Católico & $5 / 41,7$ \\
\hline Evangélico & $7 / 58,3$ \\
\hline \multicolumn{2}{|l|}{ Tipo de Cirurgia (n/\%) } \\
\hline Revascularização miocárdica & $8 / 66,67$ \\
\hline Troca ou plastia de válvula & 4 / 33,33 \\
\hline Tempo de internamento (md $\pm d p)$ & $22,58 \pm 14,39$ \\
\hline Tempo de pré-operatório ( $\mathrm{md} \pm \mathrm{dp}$ ) & $18,42 \pm 11,86$ \\
\hline Cirurgia cardíaca prévia (n/\%) & $1 / 8,3$ \\
\hline
\end{tabular}

Quanto à cirurgia, 33,33\% tinham por indicação a troca ou plastia de válvulas cardíacas e $66,67 \%$ a revascularização miocárdica. Apenas um paciente $(8,33 \%)$ já havia sido submetido à cirurgia cardíaca. O tempo médio de internamento até a entrevista foi de 22,58 $\pm 14,39$ dias, com intervalo de 18,42 $\pm 11,86$ dias entre a ciência da decisão cirúrgica e a entrevista. (tabela 1)

Na análise do bem-estar espiritual, todos os pacientes da amostra apresentaram valor máximo para o domínio bem-estar religioso, ligado às questões da relação com Deus. Houve variação quanto ao bem-estar existencial, que apresentou média elevada $(48,25 \pm 7,48)$. No total, o valor médio elevado da amostra $(108,25 \pm 7,48)$ condiz com o critério de inclusão. (tabela 2)

Tabela 2: Avaliação do bem-estar espiritual dos pacientes no pré-operatório de cirurgia cardíaca. Recife, 2014.

\begin{tabular}{|c|c|c|c|}
\hline Variável & $\mathrm{MD} \pm \mathrm{DP}$ & Mínimo & Máximo \\
\hline $\begin{array}{l}\text { Bem-Estar Reiligio- } \\
\text { so (BER) }\end{array}$ & $60,0 \pm 0,0$ & 60 & 60 \\
\hline $\begin{array}{l}\text { Bem-Estar Existen- } \\
\text { cial (BEE) }\end{array}$ & $48,25 \pm 7,48$ & 35 & 58 \\
\hline $\begin{array}{l}\text { Bem-Estar Espiritu- } \\
\text { al Total (BEET) }\end{array}$ & $108,25 \pm 7,48$ & 101 & 118 \\
\hline
\end{tabular}

Relações entre Deus, adoecimento e cirurgia cardíaca

Esta categoria reuniu visões comuns acerca das relações entre Deus e o momento estressante pelo qual os pacientes estavam se submetendo.

$\mathrm{O}$ adoecer apresentou-se nas falas ora como castigo, punição, carreando grande conteúdo de culpa, ora como provação. Considerando que a doença cardíaca sabidamente está relacionada a fatores de risco que podem ser modificáveis, estar na condição de necessitar de cirurgia pelo avançar da doença foi associado, por vezes, como punição pela história pregressa e o descuido com a própria saúde.

Devo estar pagando algum pecado. (P2)

Quem procurou essa doença fui eu. (P11)

A vida é como uma plantação: o que você planta você colhe. (P11)

Deus, de modo geral, não foi associado à culpa pela doença, mas por algum motivo per- 
mitiu que os entrevistados adoecessem severamente e tivessem de ser submetidos à cirurgia de tão grande porte.

Ele não quer nada de ruim, mas permite que aconteça. (P5)

Deus permitiu. Só tô doente porque Deus permitiu. (P10)

Nesse aspecto, alguns pacientes referiam não conhecer bem o porquê de adoecerem do coração, mas afirmavam que Deus sabia o motivo, enquanto outros conseguiam dar sentido ao momento em que se encontravam.

A gente não faz tudo que ele manda, por isso a gente é merecedor. (P1)

A gente fica doente para se chegar mais aos pés do Senhor. (P2)

Outros encontravam sentido para a cirurgia na provação, associando sua situação atual a questões de sua própria vida ou aspectos de cunho teológico, como o pecado original.

Nós adoecemos pelos nossos pecados, desde Adão e Eva. (P3)

Se Jesus sofreu, imagine nós! (P3)

Eu não sei bem o que fiz para merecer, mas Deus me deixou doente para eu aprender a confiar mais nele. (P4)

Foi para dar valor ao que a vida tem de bom. A gente esquece muito de agradecer, mas pede demais. (P11)

As últimas falas também retratam que, para os pacientes cristãos, a doença não é apenas uma forma de Deus castigar uma transgressão nem está apenas associada ao pecado original, mas o adoecer, mesmo que drasticamente, é uma forma que Deus se utiliza também para fazer o indivíduo se reaproximar d'Ele ou de sua lei ou mandamentos.

Deus e o enfretamento da doença e do trâmite cirúrgico

Submeter-se à cirurgia cardíaca mostrou-se como um evento gerador de estresse e angústia, sob o ponto de vista do risco cirúrgico e das possiblidades de limitação após o procedimento, tanto quanto às questões relativas ao próprio período pré-operatório.

Tenho várias vezes a vontade de ir embora e desistir. (P11)

Eu me sinto como se fosse um pesadelo, como se eu estivesse dormindo e fosse acordar sem a doença. (P11)

Em relação ao período pré-operatório, o intervalo prolongado em internamento do evento agudo à definição cirúrgica e desta ao procedimento aprofunda o sentimento de angústia existencial - relacionada às questões de vida diária, à cissão na rotina, a mudanças não planejadas - e a possibilidade de ansiedade e depressão.

O processo é muito lento aqui. É massacrante a espera. (P9)

Meus problemas ficam na mão do povo para os outros resolverem. (P9)

Esse tempo de espera intensifica uma questão que geralmente se apresenta na doença cardíaca avançada antes do internamento: 
a impossibilidade da participação na igreja, no culto e atividades religiosas habituais. As falas a seguir emergiram desse ponto:

Só me preocupo em ir a minha Igreja. Tô parado... (P10)

Antes de vir para a emergência eu já estava sem ir à lgreja porque não dava para subir a ladeira até lá! Também não aguentava o culto todo, cansava muito, não conseguia cantar os hinos. (P8)

Uma confiança singular em Deus e em seus atributos teológicos comuns a qualquer religião, como justiça, sabedoria e bondade, mostraram-se na base da participação da presença de Deus na constituição de um complexo de coping religioso e espiritual importante.

O homem é tão estudado e não faz um cacho de banana tão perfeito! Se Deus me colocou nessa sabe me tirar também. (P8)

Se o Evangelho fala e eu creio, não tenho preocupação. (P10)

Minha força vem de Deus, confio n'Eele, Ele quer o melhor para todos nós!(P3)

Mesmo para os pacientes que não conseguem encontrar sentido para o adoecimento nem reconhecer a intervenção direta de Deus em favorecer o melhor prognóstico com a possiblidade de recuperação ou cura, a próxima fala reflete que a confiança em Deus se projeta para além desta vida, embasada na crença espiritualista comum às religiões cristãs de vida após a morte. Independente do desfecho da doença, para o paciente, a intervenção divina pode se dar na salvação de sua alma. Esse sentimento era um dos eixos principais da estratégia de enfrentamento elaborada pelo paciente.

Dessa doença eu só espero uma coisa: minha salvação! Ele me levando ou eu ficando mais, não importa, só quero minha salvação. (P6)

Os pacientes, de modo geral, pouco referiram à possibilidade de intervenção direta de Deus na sua cura por meio de milagres, possivelmente pelo avançar da doença e a proximidade com a cirurgia. A paciente a seguir não descarta a possiblidade de cura milagrosa, no entanto demonstra aceitação do trâmite cirúrgico confiando que a equipe médica será o instrumento de que Deus se servirá para sua cura.

Deus é quem cura as enfermidades. Ele usa os médicos, mas também faz milagres. (P12)

Entre os pacientes, alguns relataram evidências pessoais da manifestação divina que serviram como reforço positivo para o enfrentamento e incremento significativo na confiança no procedimento. $O$ primeiro deles foi entrevistado dias após receber um marca-passo provisório. Durante o procedimento, antes da sedação, relata que:

Eu vi um anjo de branco na sala. Estavam todos de verde e só ele de branco. Jesus mandou um anjo para segurar na mão dos médicos. (P7)

Alguns outros registram a intervenção de Deus de forma mais íntima, por meio da oração.

Deus falou comigo que eu tinha que passar para dar meu testemunho dele. (P2)

Deus fala comigo quando eu oro e eu sei que vai dar tudo certo. (P10) 
Por fim, transcreve-se o relato da manifestação de Deus por meio de um sonho. O paciente a seguir descreveu com nítida lembrança e riqueza de detalhes a experiência onírica. Sem ajuda externa, o mesmo extraiu do sonho significados que lhe deram a condição de aceitação da doença e a força necessária ao trâmite cirúrgico.

Ah, doutor, eu sei que vou ficar bem, vai dar tudo certo! [...] Deus falou comigo. Eu tive um sonho que era Deus querendo falar comigo. [...] Eu sonhei que estava numa feira bem movimentada com muitos pobres e gente doente, um lugar feio e sujo. Ai, um anjo desceu do céu uma escada gigante, dourada, cheia de luz e disse que ela levaria até o céu. Todo mundo correu para a escada para sair daquele lugar feio e sujo. No pé da escada, tinha escrito:'Só suba se tiver fé.'Todo mundo foi subindo, tinha gente que nem lia. Quando a gente foi passando da nuvem, um monte de gente começou a cair. E o anjo me disse que quem tava caindo era porque não tinha fé. Teve gente que começou a voltar do meio do caminho, porque dizia que tinha fé, mas sabia que lá dentro, de verdade, não tinha. Eu continuei subindo. Cheguei muito alto que não via nada embaixo das nuvens. Aí, vi no fim da escada uma igrejinha com uma cruz. E o anjo disse: 'José, Jesus tá lá dentro dessa igrejinha te esperando, mas tu só entra se tiver fé!' $E$ eu fiquei feliz porque eu ia ver Jesus, eu tenho fé e já tinha subido aquilo tudo! Aí, o anjo disse: 'José, volta tudo de novo, um dia tu vai ver Jesus se continuar com fé, mas volta que ainda está longe da tua hora.' Depois desse sonho, veio a dor com tudo e eu passei mal e vim pra cá. Por isso, eu sei que dessa vez eu não morro! [...] Estou tranquilo, doutor, não é minha hora não! (P3)

A experiência do sonho deu-se antes da admissão à emergência, sem o paciente ter apresentado previamente angina ou qualquer outro sintoma cardíaco. A certeza do sucesso do procedimento cirúrgico ficou claro após o caráter de anunciação do sonho e a nítida lembrança de que não era sua hora de "entrar na igrejinha do céu e conhecer Jesus".

\section{DISCUSSÃO}

A amostra foi selecionada tendo em vista aprofundar-se na questão da relevância de Deus para os pacientes no pré-operatório de cirurgia cardíaca. Considerando a seleção a partir de um alto escore de bem-estar espiritual e religioso como critério de inclusão, o estudo não evidenciou questões de coping negativo, como o questionamento à vontade de Deus etc.

Espiritualidade pode se expressar em diversas formas no processo saúde-doença, incluindo a busca por significado e propósito para a vida, conexões com família, amigos, natureza e com Deus $^{(10)}$. A situação do adoecimento é desencadeadora, na maioria das vezes, de profundas reflexões acerca da relação do individuo consigo, com seus pares, seus grupos sociais e suas crenças acerca do sagrado.

O pré-operatório é um período do adoecimento com crises profundas, referido como um período de vulnerabilidade emocional em virtude da exposição do indivíduo as questões que emergem envoltas em incertezas (recuperação, sequelas, finitude etc.) ${ }^{(11)}$. Um estudo no pré-operatório revelou que os pacientes apresentaram, ao receber a notícia da cirurgia, muitos sentimentos de apreensão, como medo, 
preocupação, ansiedade, cisma e nervosismo e que, com o passar do tempo, os sentimentos vão mudando de forma positiva para a esperança diante da possibilidade de cura e reabilitação, sentimento de tranquilidade (vinda da fé em Deus, de ver os colegas já operados e de saber que o risco de vida é maior se não operar) e de alívio por reconhecerem que é necessário para continuarem vivendo ${ }^{(5)}$. Esse estudo, ao acompanhar as mudanças positivas ao longo do internamento, reforça a necessidade pressuposta de se aproveitar o tempo de definição cirúrgica e preparo do paciente para intervenções educativas e no âmbito da espiritualidade e religiosidade.

A crença no controle de Deus sobre os eventos da vida abrangendo do simples e cotidiano aos momentos decisórios, bem como outros construtos acerca dos atributos de teológicos de Deus, tem sido evidenciada em associação positiva a melhores índices de bem-estar, quando avaliado em domínios subjetivos ${ }^{(12)}$. Em uma amostra de pacientes com HIV/AIDS, ficou comprovada a associação estatisticamente significativa entre uma visão positiva de Deus e fatores psicológicos, como depressão, mas também quantitativos, como a taxa de linfócitos CD4 ${ }^{(13)}$.

Em uma amostra de 150 pacientes com câncer, foi evidenciado que o incremento ou estímulo às crenças e práticas religiosas e a confiança em Deus favoreceu melhor aceitação da doença e confrontação aos problemas psicológicos. Das estratégias de coping religioso utilizados, a dimensão que mais se mostrou eficaz na redução dos níveis de depressão foi a relação com Deus ${ }^{(14)}$.

Embora o contato divino seja uma dimensão avaliada por outras escalas, visto a relevância desse aspecto no coping religioso/espiritual, foi desenvolvida e validada recentemente uma escala própria, a Perceived Support From God Scale, ainda não traduzida e validada para o português nem entre populações não cristã ${ }^{(13)}$. A relação com Deus no momento da dor e da doença pode ser medida, ainda, em termos de relação com o amor divino. Uma escala tipo likert, a Sorokin Multidimensional Inventory of Love, é utilizada para avaliar a percepção do individuo com amor a Deus e o amor dispensado a Ele $^{(16-17)}$.

Em uma pesquisa com dez pacientes sobreviventes da doença cardíaca grave e nove sobreviventes do câncer, as falas se assemelhavam em muito ao extraído no presente estudo, notadamente quanto às visões sobre Deus e o adoecimento, a aproximação que houve com Deus após a doença e a força que haviam ganhado a partir da conexão com uma força superior $^{(10)}$.

Em um estudo prospectivo realizado com 142 pacientes para avaliar implicações da religiosidade e recuperação da cirurgia cardíaca, evidenciou-se que a forte crença religiosa estava relacionada a menos complicações, incluindo a depressão, e menor tempo de internamento, sendo mais significativa a crença religiosa que o suporte social ${ }^{(11)}$. Ainda no tocante ao estudo citado, a crença religiosa positiva apresentou-se como um suporte mais importante e significativo e como melhor preditor de resultados que o otimismo, a partir do que se depreende o quanto os aspectos espiritualidade e religiosidade são valorosos para o enfrentamento e o quanto devem ser estudados ${ }^{(11)}$.

Cabe ressaltar que esses termos ainda carecem de melhor definição e validação diferencial, sendo muitas vezes encarados no meio acadêmico da mesma forma. Considerando que religiosidade está para a religião assim como espiritualidade está para o transcendente, autores renomados na área sugerem que se prefira utilizar-se do segundo ao abordar os pacientes, em virtude da diferença de religiões e sistemas de crenças encontradas na população ${ }^{(1)}$.

Duas semanas após a cirurgia de revascularização miocárdica, 177 pacientes foram 
entrevistados, de forma a revelar que a prece estava associada ao menor número de complicações, enquanto o senso de reverência no contexto secular estava relacionado a menos complicações e menor tempo de internamento ${ }^{(18)}$. O senso de reverência em relação a Deus integra o sistema de crença da maioria das pessoas religiosas.

Quanto à confiança em Deus manifestada na confiança em sua vontade, um estudo qualitativo com transplantados renais revelou em uma das categorias temáticas que os pacientes reconheciam a provação como vontade de Deus ${ }^{(17)}$. Outro estudo, comparando entre pacientes depressivos em tratamento clínico, concluiu que os pacientes que creem em Deus têm menores índices de desesperança, atitudes disfuncionais e sintomas depressivos ${ }^{(19)}$.

A possibilidade da intervenção de Deus por meio do milagre, ou seja, do evento acima das possibilidades cientificamente reconhecidas e as quais as evidências na área de saúde embasam, mantém para o paciente a possiblidade de barganhar com Deus sobre sua própria saúde ${ }^{(20)}$.

A experiência mística por meio de visões, audição e dos sonhos, como referido pelos entrevistados, gera uma interpretação e favorece o encontro com o sentido para sua vida no momento difícil e probatório, além de reforçar o conceito de Deus como real e palpável, em constante interação com os humanos ${ }^{(20)}$.

\section{CONCLUSÃO}

Apesar do preparo teórico prévio dos pesquisadores e a experiência profissional angariada sob uma abordagem holística - o que motiva o interesse acadêmico contínuo sobre o tema, abordar os pacientes e conduzir a entrevista norteada pela questão proposta para atender os objetivos mostrou-se desafiador perante a subjetividade do assunto e dos termos relacionados.

Os achados encontrados são relevantes ao mostrar uma direção na compreensão do efeito da crença em Deus no enfrentamento do trâmite cirúrgico, abrindo perspectivas para que em pesquisas subsequentes sejam investigadas as mesmas relações em outras populações, em culturas e religiões diversas, e com situação emocional diferente, considerando que os pacientes foram selecionados a partir de altos escores de bem-estar espiritual, mas que há pacientes que não conseguem se manter da mesma forma.

As questões de transcendência, daquilo que está além do próprio individuo, avolumam-se no adoecimento, sobretudo às vésperas da cirurgia, e requerem atenção dos profissionais de saúde. Os envolvidos no cuidado devem ter um olhar especial para as questões da religiosidade, visto que dentre os aspectos subjetivos do paciente, espiritualidade e religiosidade são dimensões negligenciadas, apesar da grande relevância para o enfretamento das doenças.

A religiosidade dos pacientes mostrou-se em profunda relação com a crença em Deus. Este estudo evidenciou significativas relações positivas entre a crença em Deus e o enfrentamento da doença, em uma perspectiva que precisa ser cada vez mais estudada.

A doença não foi relacionada veementemente ao castigo divino, mas o conhecimento da progressão da doença cardíaca relacionada a hábitos de vida modificáveis revelou-se ligado a sentimentos de culpa.

Por fim, a crença em Deus e suas manifestações repercutiram positivamente no encontro com um novo sentido para o trâmite cirúrgico, mostrando-se encorajadora e sustentadora da motivação em submeter-se à cirurgia. 


\section{REFERÊNCIAS}

1. Lucchese FA, Koenig HG. Religion, spirituality and cardiovascular disease: research, clinical implications, and opportunities in Brazil. Rev bras cir cardiovasc 2013 [cited 2015 aug 20]; 28(1):103-28. Available from: http://www.scielo.br/pdf/rbccv/ v28n1/v28n1a15.pdf

2. Ai Al H, Ladd KL, Peterson C, Cook CA, Shearer M, Koenig $\mathrm{HG}$. Long-term adjustment after surviving open heart surgery: the effect of using prayer for coping replicated in a prospective design. Gerontologist [internet]. 2010 [cited 2015 aug 20]; 50(6): 798-809. Available from: http://www. ncbi.nlm.nih.gov/pmc/articles/PMC2982210/ pdf/gnq046.pdf

3. Kalkhoran MA, Karimollahi M. Religiousness and preoperative anxiety: a correlational study. Ann Genl Psychiatry [internet]. 2007 [cited 2015 aug 20]; 6:17. Available from: http://www.ncbi.nlm. nih.gov/pmc/articles/PMC1947984/pdf/1744-859X-6-17.pdf

4. Umann J, Guido LA, Linch GFC. Estratégias de enfrentamento à cirurgia cardíaca. Cienc Cuid Saude [internet]. 2010 [cited 2015 aug 20]; 9(1):67-73. Available from: http://periodicos. uem.br/ojs/index.php/CiencCuidSaude/article/ view/10531/5738

5. Vargas TVP, Maia EM, Dantas RAS. Sentimentos de pacientes no pré-operatório de cirurgia cardíaca. Rev Latinoam Enferm [internet]. 2006 [cited 2015 aug 20]; 14(3): 383-388. Available from: http://www.scielo.br/pdf/rlae/v14n3/ pt_v14n3a12.pdf

6. Koerich C, Baggio MA, Erdmann AL, Lanzoni GMM, Higashi GDC. Revascularização miocárdica: estratégias para o enfrentamento da doença e do processo cirúrgico. Acta Paul Enferm [internet]. 2013 [cited 2015 aug 20]; 26(1):8-13. Available from: http://www.scielo.br/pdf/ape/v26n1/03.pdf

7. Ai Al H. Divine love and deep connections: a long-term followup of patients surviving cardiac surgery. J Aging Res [internet]. 2011 [cited 2015 aug 20]. Available from: http://www.ncbi.nlm.nih. gov/pmc/articles/PMC3124964/

8. Ai Al H, Wink P, Shearer M. Fatigue of survivors following cardiac surgery: positive influences of preoperative prayer coping. $\mathrm{Br} \mathrm{J}$ Health Psychol [internet]. 2012 [cited 2015 aug 20]; 17(4):724-42. Available from: http://www.ncbi.nlm.nih.gov/ pubmed/22524258

9. Marques LF, Sarriera JC, Dell'aglio DD. Adaptação e validação da Escala de Bem-estar Espiritual (EBE). Aval Psicol. 2009 [cited 2015 aug 20]; 8(2): 179-186 Available from: http://pepsic.bvsalud. org/pdf/avp/v8n2/v8n2a04.pdf

10. Young WC, Nadarajah SR, Skeath PR, Berger NA. Spirituality in the context of life threatening illness and life-transforming change. Palliat Supportive Care. 2014. 1-8

11. Contrada RJ, Goyal TM, Cather C, Rafalson L, Idler EL, Krause TJ. Psychosocial factors in outcomes of heart surgery: the impact of religious involvement and depressive symptoms. Health Psychol. [internet] 2004 [cited 2015 aug 20]; 23(3):227-38. Available from: http://psycnet.apa.org/journals/ hea/23/3/227/

12. Schieman S, Alex B, Christopher GE. Religious Involvement, Beliefs about God, and the Sense of Mattering among Older Adults. J Sci Study of Relig. 2010; 49:517-35.

13. Ironson G, Stuetzle R, Ironson D, Balbin E, Kremer $\mathrm{H}$, George A. View of God as benevolent and forgiving or punishing and judgmental predicts HIV disease progression. J Behav Med [internet]. 2011 [cited 2015 aug 20]; 34(6):414-25. Available from: http://www.ncbi.nlm.nih.gov/ pubmed/21340531

14. Haghighi F. Correlation between religious coping and depression in cancer patients. Psychiatr Danub. 2013; 25(3):236-240

15. Hamilton JB, Carte JK, Lynn MR. Reliability and validity of the perspectives of Support From God Scale. Nurs Res. 2010; 59(2): 102-109.

16. Levin J, Kaplan BH. The Sorokin Multidimensional Inventory of Love Experience (SMILE): development, validation, and religious determinants. Rev Relig Res. 2010; 51(4): 380-401

17. Ghahramani N, Wang C, Sanati-Mehrizy A, Tandon A. Perception about transplant of rural and urban patients with chronic kidney disease: a qualitative study. Nephro Urol Mon. 2014; 6(2): e15726.

18. Ai, AL, Wink P, Tice TN, Bolling SF, Shearer M. Prayer and reverence in naturalistic, aesthetic, and socio-moral contexts predicted fewer com- 
plications following coronary artery bypass. J Behav Med. [internet] 2009 [cited 2015 aug 20];32(6):570-81. Available from: http://www. ncbi.nlm.nih.gov/pubmed/19856203

19. Peselow E, Pi S, Lopez E, Besada A, Ishak WW. The impact of spirituality before and after treatment of major depressive disorder. Innov Clin Neurosci. 2014;11(3-4):17-23

20. Manglos ND. Faith Pinnacle Moments: Stress, Miraculous Experiences, and Life Satisfaction in Young Adulthood. Sociol Relig. 2013, 74:2 176-198
Todos os autores participaram das fases dessa publicação em uma ou mais etapas a seguir, de acordo com as recomendações do International Committe of Medical Journal Editors (ICMJE, 2013): (a) participação substancial na concepção ou confecção do manuscrito ou da coleta, análise ou interpretação dos dados; (b) elaboração do trabalho ou realização de revisão crítica do conteúdo intelectual; (c) aprovação da versão submetida. Todos os autores declaram para os devidos fins que são de suas responsabilidades o conteúdo relacionado a todos os aspectos do manuscrito submetido ao OBJN. Garantem que as questões relacionadas com a exatidão ou integridade de qualquer parte do artigo foram devidamente investigadas e resolvidas. Eximindo, portanto o OBJN de qualquer participação solidária em eventuais imbróglios sobre a materia em apreço. Todos os autores declaram que não possuem conflito de interesses, seja de ordem financeira ou de relacionamento, que influencie a redação e/ou interpretação dos achados. Essa declaração foi assinada digitalmente por todos os autores conforme recomendação do ICMJE, cujo modelo está disponível em http://www. objnursing.uff.br/normas/DUDE_final_13-06-2013.pdf

Recebido: $14 / 02 / 2015$

Revisado: 20/08/2015

Aprovado: 20/08/2015 